\title{
Yesterday, Today and Future of the Engineering Management Body of Knowledge
}

\begin{abstract}
Young engineers are often promoted to leadership roles such as a team leader or a manager within 3 to 6 years of graduating from an undergraduate degree in a technical area. To be competent and successful in their leadership role engineers need to update their engineering management knowledge and learn new skills. The purpose of engineering management body of knowledge (EMBOK) is to delineate the knowledge, skills, and competency areas that are applicable to the engineering management discipline. It basically answers the question, "What does it take to be an effective engineering manager?" The EMBOK is based on a validated study and can be used for curriculum development, certification exams, and professional development programs. This paper describes the 11 domains that are included in the EMBOK and discuss the future publication of the EMBOK Guide. American Society for Engineering Management (ASEM) offers two certification exams based on the EMBOK, Associate Engineering Manager (AEM) and Professional Engineering Manager (PEM).These certification exams can help an individual in the engineering management profession to show that they have kept up in the field and possess the necessary skills and competency to practice in the discipline. A detailed description of this certification program is included in this paper. The future of EMBOK and the certification program is also discussed.
\end{abstract}

Keywords: body of knowledge, engineering management, certification exam, engineering manager, competency areas

Manuscript received December 2, 2014; accepted February 27, 2015

Hiral Shah $(\varangle)$

St. Cloud State University, Maple Grove, MN 55369, USA

Email: hashah@stcloudstate.edu

Walter Nowocin

Medtronic Inc., Mounds View, MN 55112, USA

\section{EMBOK and its history}

Young engineers are often promoted to leadership roles such as team leaders or managers within 3 to 6 years of graduating with a technical undergraduate degree. Although they possess a strong technical background they are often not successful in their leadership roles and fail to achieve the managerial goals assigned to them. The reason is mainly because they lack the management knowledge and skills.

To be successful requires that engineering management graduates be effective problem solvers, function well on the multi-disciplinary teams, communicate effectively in writing and verbally, recognize ethical issues and make appropriate decisions, recognize the importance of environmental factors in engineering decisions, and have an understanding of the economics and business aspects of engineering. Failure in this area can mean lost or upset clients, unprofitable projects, missed deadlines, disgruntled fellow employees, and in the worst case termination of the young engineer.

The engineering management body of knowledge (EMBOK) outlines the competency areas that should be possessed by professionals working in the field of engineering management. This paper describes the eleven domains of the body of knowledge and provides information about the certification exam in engineering management which can be used to validate an individual's knowledge and skills in the discipline. A further discussion on the future plans of the certification program and the body of knowledge is also described.

\subsection{What is EMBOK?}

The American Society for Engineering Management (ASEM) defines engineering management as an art and science of planning, organizing, allocating resources, and directing and controlling activities that have a technological component. The EMBOK delineates the knowledge and skills that are needed to perform in the engineering management discipline. It basically answers the question, 
"What does it take to be an effective engineering manager?" and provides a common vocabulary for the engineering management discipline (Shah, 2012).

\subsection{History of EMBOK}

The first edition of "A Guide to the EMBOK" was published by the American Society of Mechanical Engineers (ASME) under the umbrella of engineering management certification international (EMCI). ASEM was only peripherally involved in its development. The 2 nd edition was published in 2009 with ASME as the copyright holder and had significantly more input from ASEM's academics and professionals. The 3rd edition of EMBOK was published in 2012 with ASEM as the copyright holder and had major upgrades to the content and format. The current 3rd edition of EMBOK includes eleven domains, with four new domains namely: instruction to engineering management, operations and supply chain management, management of technology, research and development, systems engineering.

\subsection{Validation of the EMBOK}

The competency areas in the EMBOK were validated through a role delineation study on the engineering management professionals in 2014. These professionals were asked to rate the competency areas on a five-point Likert scale and were also asked to add any new topics that are important for a practitioner to know in the engineering management field. The results of the study will be published in the proceedings of the 2015 ASEM conference.

\section{Domains of the EMBOK}

There are eleven domains of the EMBOK and they represent the best information available in the field of engineering management. The domains are derived from analyzing content areas from published books, studies on engineering management competency areas, and input from subject matter experts from academia and industry. The eleven domains are: introduction to engineering management; leadership and organizational management; strategic planning; financial resource management; project management; operations and supply chain management; marketing and sales management in engineering organization; management of technology, research and development; systems engineering; legal issues in engineering management; and professional codes of conduct and ethics. Each domain is summarized below using information extracted from the $3 \mathrm{rd}$ edition of "A Guide to the EMBOK'(Shah, 2012).

\subsection{Introduction to engineering management}

This domain provides an introductory framework for the engineering management discipline. It defines planning, organizing, allocating resources, and directing and controlling activities that are involved in the field. Other themes discussed in this domain are: engineering management skills, role of practicing engineering managers, and tomorrow's challenges.

\subsection{Leadership and organization management}

When engineers are promoted into management positions without formal management training or much management experience, they likely lack a thorough understanding of key management principles. This is unfortunate, as such principles provide managers - both new and seasoned the guidance they need to navigate day-to-day management challenges, especially those involving the management of people.

Domain 2 examines a number of these management principles, focusing in particular on the management styles and organizational structures that are most conducive to managing professionals - including engineers - whose primary labor is intellectual.

Other themes discussed in this domain are: schools of management thought, managing and motivating knowledge workers, organization structure, management systems and systems thinking, leadership, human resources management, and teaming.

\subsection{Strategic planning}

Strategic planning models fall into two major categories, planning and management. Strategic planning has been defined in the EMBOK as the process to establish, implement, correct, and continuously improve a corporate strategic plan. Strategic management is defined and the tools and techniques used to implement strategy and the efforts needed to quickly respond to special events that occur before the formal planning process recycles are discussed.

Other themes discussed in this domain are: importance of strategic planning, strategic planning process, strategic management, strategy formulation, executing the strategy, strategic performance measurement, and deploying lessons learned.

\subsection{Financial resource management}

For almost all activities that engineers are engaged in, and in particular engineering management, money is an appropriate tool to measure the value of the output. The principles of sound engineering design are all based on the concept of producing the maximum benefit for the 
minimum expenditure of monies. Only through an understanding of the processes involved in the accounting of money can an engineering manager ensure that the decisions made will optimize the use of financial resources and create the greatest value for their organizations.

Other themes discussed in this domain are: accounting finance budgets engineering economics, and cost and benefit estimating.

\subsection{Project management}

Project management is the application of knowledge, skills, tools, and techniques to project activities to meet the project requirements. Because the number of projects undertaken by organizations has increased dramatically, project management has become a critical skill for most companies. The EMBOK refers to the PMBOK(project management body of knowledge) Guide as the accepted best practices for the project management profession and describes the integrated processes as: initiating, planning, executing, monitoring and controlling, and closing.

\subsection{Operations and supply chain management}

The ultimate success of any commercial organization depends upon its ability to determine and satisfy its customers' needs. Today, organizations focus on quality, speed, efficiency, and customer value to be globally competitive, and the long-term sustainability of any organization depends on its commitment to continuous improvement.

Themes discussed in this domain are: quality management, process improvement, operations management, inventory management and supply chain, facilities management, and measuring supply chain performance.

2.7 Marketing and sales management in engineering organizations

Marketing drives the sales process. Strategic marketing efforts assist organization attempts to determine what customers need and want and further guide development of the strategy for bringing the product to the marketplace. While sales and marketing are part of the same "systems" they are distinct in their aims. Sales focus on the attempts to motivate potential customers to purchase a product or service.

Themes discussed in this domain are: sales and advertising practices, customer satisfaction strategies, marketing and branding techniques, product portfolio analysis, global trade and international operations, and pricing strategies.

2.8 Management of technology, research, and development

Technology is a key to business success. The development and use of technologies provide organizations with a competitive advantage to improve the human condition.

Themes discussed in this domain are: overview, managing, and developing technology and research into new products.

\subsection{Systems engineering}

Systems engineering is a multi-disciplinary approach that deals with large complicated and complex systems. The main focus of systems engineering is on system development but it also takes into account the full life cycle of the system. Typically, the systems engineering process is a requirements-driven process, using requirements to ensure that the system developed meets all of the stated customer's needs.

Themes discussed in this domain are: systems engineering method, implementing systems engineering, and current focus areas in systems engineering.

\subsection{Legal issues in engineering management}

Business law takes on many forms and regulates a variety of business entities and commercial transactions. Laws are designed to protect all parties through directing how terms and conditions, specific performance expectations, breach of contract agreements, etc.

Themes discussed in this domain are: business contracts, environmental issues, human resources, intellectual property, warranties/liability/insurance, and regulatory requirements/codes/standards.

\subsection{Professional codes of conduct and ethics}

Ethics address what behavior is considered right and wrong, good and bad - what a person should and should not do. Ethics is not about law per se, although many behaviors that are illegal are also unethical. Many unethical behaviors are forbidden by law, but other unethical behaviors are perfectly legal. Several organizations, including professional societies, create codes of ethics to help members develop the ability to make effective decisions and follow them up with ethical actions.

Other themes discussed in this domain are: the nature of ethics, stakeholders and ethics, ethical theories, principles of ethics for engineers and managers, practical ethical decision-making, and professional codes of conduct.

\section{Application of EMBOK}

EMBOK serves as a foundational guide for those practicing in the field of engineering management. The EMBOK can be used for curriculum development, training programs, professional development programs, certification exam development, program certification, and in many 
other areas. It serves as a framework for advancement in the field. The "A Guide to the EMBOK" can be viewed as a foundational reference for the discipline.

Two certification exams based on the EMBOK are offered by ASEM: Associate Engineering Manager (AEM) and Professional Engineering Manager (PEM) under the Engineering Manager Professional Certification (EMPC) program.

\subsection{EMPC}

EMPC program offered by ASEM serves the purpose of addressing the issue of identifying and employing skilled professionals in the engineering management discipline. Moreover, an engineering manager professional can validate their knowledge and skills by taking the certification exam.

ASEM has created two levels of professional certifications: AEM and PEM. There are eligibility criteria to apply for the certification exam. Re-certification at the AEM or PEM level can be achieved by accumulating 45 professional development units (PDUs) over the preceding three years and by paying a re-certification fee.

\subsection{AEM}

This professional certification is designed for young technical professionals seeking to establish credentials in preparation for early technical management or supervisory assignments. Candidates with bachelor's or master's degree (from a non-ASEM certified program) in engineering management are required to possess any combination of $40 \mathrm{~h}$ of documented training related to three or more domains of the EMBOK and/or any combination of two years of professional experience or managing knowledge workers in a technology- based enterprise (www. asem. org). These candidates need to appear for the AEM exam that has 100 multiple choice questions based on the EMBOK and achieve at least 70 percent to pass and get certified as AEM. The AEM certification is valid for three years.

The candidates with master's degree in engineering management from ASEM certified program can get the AEM title by paying the certification fee and they don't need to take the AEM exam.

\subsection{PEM}

This professional certification is designed for experienced technical managers seeking to validate their skills and experience with a professional certification. The PEM certification is valid for three years. Candidates seeking to take the PEM certification exam are required to meet the experience and education eligibility criteria. The PEM exam contains 200 multiple choice questions based on the EMBOK to be completed in four hour time frame. A candidate should obtain 70 percent passing score to get certified.

Candidates with $\mathrm{Ph}$. D. in engineering management and three years of professional experience in managing projects or programs can get the PEM title by paying the certification fees and they need not appear for the certification exam.

\section{Future of EMBOK}

Engineering management discipline has progressed and is getting attention in the labor market. The EMBOK needs to be updated so it reflects the developments in the field and meets the need of industry. ASEM plans to publish new edition of EMBOK Guide at an interval of every 3 to 4 years to meet the demands of the industry, academia and the global EM community as a whole.

The future edition of " $A$ Guide to the EMBOK" will present framework on how the domains are integrated and related to each other both at the project and organizational level. The plan is to provide specific information for managing knowledge workers, complex technical projects, technology driven organizations, change, and managing sustainability. Within the domains there will be more international flavor added in terms of working with virtual teams, managing cultural differences, and dealing with global challenges in the area of energy, environment, disaster management, legislation, and so forth. The competency areas within the domains will be updated based on a systematic literature review of the Engineering Management Journal (EMJ), feedback from the industry practitioners, and domain specific surveys. The certification exams will be updated based on the changes made to the EMBOK.

\section{References}

Shah, H. (2012). A Guide to the Engineering Management Body of Knowledge. [sine loco]: The American Society to Engineering Management 